\title{
Alternative E-learning Assessment by Mutual Constrain of Responsive and Constructive Techniques of Knowledge Acquisition Evaluation
}

Morales-Martinez Guadalupe Elizabeth

Cognitive Science Laboratory

Institute of Research on the University and Education

National Autonomous University of Mexico (UNAM; IISUE)

\author{
Lopez-Ramirez Ernesto Octavio \\ Cognitive Science Laboratory \\ Nuevo Leon Autonomous University \\ (UANL)
}

\author{
Daniel Velasco Moreno \\ Department of Psychology \\ National Autonomous \\ University of Mexico (UNAM)
}

\begin{abstract}
Innovation on e-assessment is presented. Here, 43 bachelor students' conceptual definitions to a course schema related concepts are obtained by using a natural semantic network technique. This allowed implementing a constructive assessment technique of students' that is complemented by a responsive assessment of student's learning based on semantic priming studies. It is argued that by using both assessment approaches in a dynamic mutually constrained way a new alternative approach to $e$ assessment can be implemented. This system presents several innovative advantages that empower students and teachers to monitor what actually takes place over the trajectory of a student learning process.
\end{abstract}

\section{Introduction}

Generally speaking, alternative assessment of learning is addressed to find out what a student knows (like in computerized adaptive testing [1]) rather than on emphasizing what a student does not know (e.g. some computer instruction systems using standard testing of knowledge [2]).

Contributions from a cognitive point of view to alternative assessment of learning have implemented tools to visually analyze mental representations changes due to learning like semantic networks [3, 4, 5] and comparable tools (concept mapping, tree diagrams, causal diagrams, etc. [6]). Computer testing of knowledge acquisition using these tools [7] empower teachers as well as students to consciously monitor controlled externalization of knowledge acquisition during a course by means of specific representational formats. This evaluation process to monitor students acquiring new semantic conceptual knowledge is termed cognitive constructive assessment and when it comes the case to asses elearning from a cognitive point of view this is one of at least two forms of cognitive approaches to asses elearning: A constructive approach and a responsive approach [8]. Here, responsive assessment of learning refers the possibility to measure unconscious and automatic learning processes underlying students' knowledge organization by using reaction times (a main assumption in cognitive memory research [9]). There is, however, a main concern on using reaction times to measure students' learning since it is believed that this approach to asses learning is prone to error and has no strong validity [8]. Rather, responsive assessment has been used to evaluate learning skills or used in applied fields of psychology like cognitive ergonomics or engineering psychology [10].

This limited state on responsive assessment, motivated new academic efforts to explore alternative assessment. For instance, Morales and colleagues $[11,12]$, recently reported a research project to innovate in educational technology by integrating responsive and constructive measurement in a single tool to evaluate online learning. They describe how a neural network can be implemented to identify whether students have integrated into their lexicon schemata related concepts (obtained by a constructive assessment approach [13]) from a school course by using semantic priming studies (a responsive assessment approach [14]). This neural network discrimination capacity is based on the idea that once a student has integrated knew knowledge in long term memory then a semantic priming effect is obtained from schemata related words only if they are long term stored (single word schemata priming $[15,16])$. This cognitive time footprint empowers a neural net to discriminate among successful and nonsuccessful students.

Even when their system might be understood as an orthogonal additive combination of constructive and responsive tools to asses learning, here it is argued that it is not so. Rather it is argued that this computerized assessment of learning represents a new form of e learning assessment where constructive and responsive assessment dynamically constrain themselves and validate each other due to its non-orthogonal contents. In order to show why this is so, some current research results obtained by this integrative approach will be presented next. 


\section{Method 1: A constructive assessment technique of learning}

First, under this cognitive approach to evaluate knowledge acquisition, students' semantic networks for course core concepts are obtained before and after course completion by using a technique called natural semantic network [13].

\subsection{Instruments}

The natural semantic network technique allows to obtain students' conceptual definitions to relevant course concepts (called target concepts) by letting students to use other semantically related concepts (called definers). Specific constrains underlying the definition technique has been tested and shown to produce definitions for the represented objects based on their meaning and not on free associations or pure semantic category membership [17]. Figure 1 shows an example of after course students' conceptual definitions to ten course schemata related target regarding Piaget's theory (ACOMMODATION, ASSIMILATION, ADAPTATION, etc.). In this technique some definers serve as definers for more than one target and are used to create an organized network of semantically that can be graphically represented by using specialized visual tools. To obtain the semantic net based as well as conceptual definitions to target concepts a specialized software implementation is used.

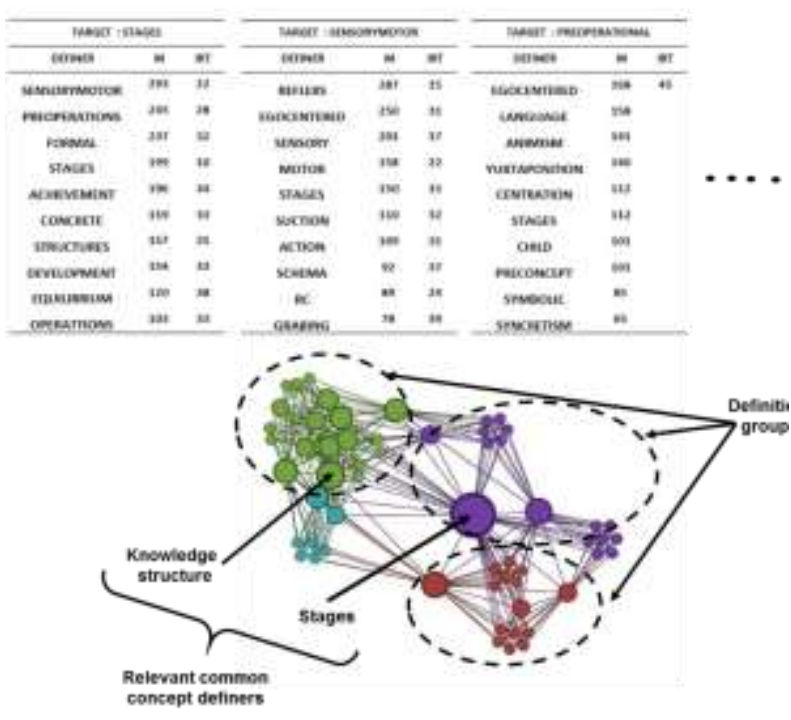

Figure 1. After calculating weight association among concept definers different semantic network visualizations can be used to determine students' knowledge structure underlying a course topic. For instance, a GEPHI network graph representation like the one shown above [13]
In order to show how to apply this network technique to constructively evaluate students' learning let us use the appointed analysis not only by using conceptual definitions from the end of the course but also from the beginning of it. That is, their conceptual definitions to the same schemata related target concepts before and after a course.

\section{Results method 1}

Figure 2 shows how before a course students generated a kind of random mental representation but at the end they showed a well clustered semantic net (smallworld structure network type [18, 19, 20]). Notice that the semantic content is not considered but only the network structure. Several network metrics can be obtained (like cluster values and other network structure values [21]) revealing network structure differences due to learning. This is a consistent result in other courses we have analyzed in the same knowledge domain or other knowledge domains.

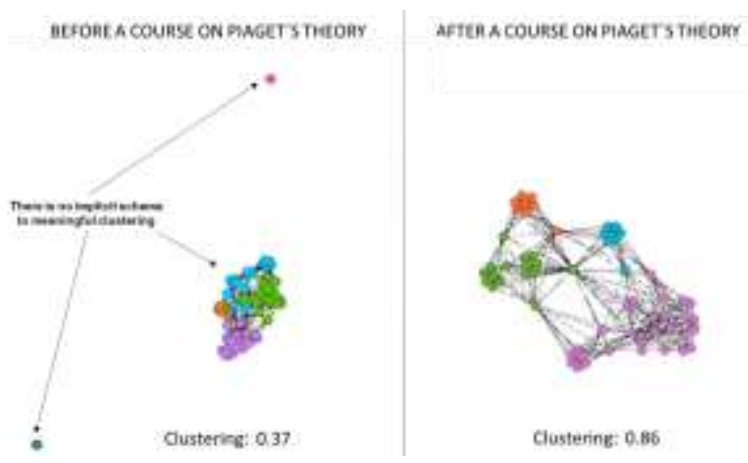

Figure 2. Learning imposes structural changes underlying concept organization in a natural semantic network (small world network structure type).

If in between centrality values for each concept in the net are reflected by node size, then the most relevant concepts to produce connectivity and meaning can be observed when the net semantic content is considered. Figure 3 illustrates this aspect before and after course learning. Before the course, the concept "Animism" is for some reason the main concept to meaningfully describe Paget's Theory.

This is not what a teacher on Piaget's theory desires. However, at the end of the course concepts like "Periods-Stages", "Schema", "Knowledge structure", "Operations", are according to teacher interviews desired central concepts to meaningful interpret such a theory. 


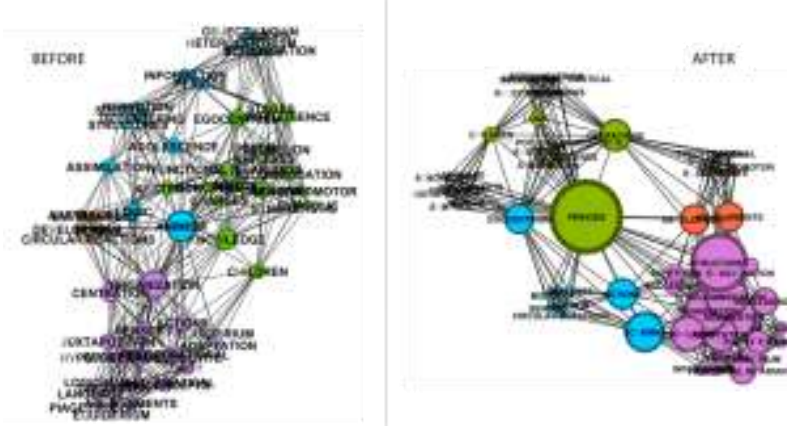

Figure 3. Semantic content before and after a course on Piaget's Theory

A more in deep analysis can be achieved by considering in between centrality of specific connectivity. For instance, the concept structure seems to be more relevant to "period/stages" than the concept "schemas". If this is really intended by a course on this topic will always depend on teaching goals. A teacher can adjust her/his lectures depending on this constructive assessment of learning.

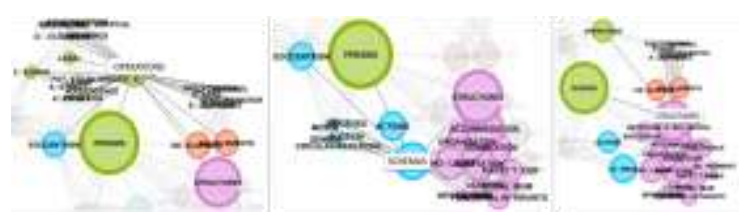

Figure 4. Specific in between centrality for the concepts "operations" (left panel), "schema" (middle panel) and "structures" (right panel)

Furthermore, following this constructive approach it is possible to use the same concept connectivity matrix underlying a visual GEPHI analysis to explore schemata properties underlying concept organization. For instance, it is possible to simulate emergent schemata behavior to visualize the effect of core concepts in the whole dynamics of schema organization $[14,22]$. Here, an interesting option would be to observe how schemata behavior semantically self organizes when one or more of concepts are omitted or altered.

The fact that students seem to reflect a different mental representation due to learning is not warranty that the new acquired knowledge will be stored in long term memory since short term retention of knowledge only to succeed an academic exam is a common practice among students. Moreover, Longterm retention of knowledge studies argue that students tend to only retain a reduced knowledge schema of previously tested knowledge [23, 24]. Since curricula agenda has course constrained times for testing knowledge acquisition, then it is not possible to wait for long periods to check for what is retained for students.
Next it is argued that by using a cognitive responsive approach these last concerns on using a constructive assessment can be explored for possible solutions.

\section{Method 2: A constructive-responsive assessment technique of learning.}

As previously appointed, a main assumption of cognitive psychology is that cognitive live occurs in time. This is relevant to memory research because it implies that the way how information is stored, organized and retrieved in long term memory imprints a footprint over cognitive information processing time. For instance, by using memory research techniques like semantic priming studies it is possible to know if associative related word pairs like BREAD - BUTTER are long term stored in the human lexicon [25]. In turn, this is important for a response assessment of learning because if new learned schemata related words are stored in long term memory then recognition times for these concepts will be significantly different from other semantically related and non-related words (e.g. schemata priming [15,16], and this priming effect would imply long term retention of this information [26]. Consequently, there is no need to wait much time after a course to know if some new acquired knowledge will be retained in the long run.

\subsection{Instrument}

Thus, either by using schemata computer simulations or natural semantic nets or both approaches, it is possible to select schemata related concepts to be used in a semantic priming study. Oversimplifying on what semantic priming is, it can be said that these memory research studies measure recognition times of semantic relevant words. Here it is assumed that if a word is relevant for a student acquired schemata, then its recognition time be significantly different from other semantically related word or none related word recognition times.

Regarding the constructive assessment of knowledge acquisition shown in Figure 3 and 4, recognition latencies of a set of Paget's theory schemata related words like the ones shown in table 1 can be compared to other semantic related (associatively) and none related words' recognition latencies. This semantic priming study is applied before and after course. It must be appointed that schemata related words in table 1 are obtained from previous after course constructive assessment of students learning with the same teacher. 
Table 1. Stimuli for the semantic priming study

\begin{tabular}{|c|c|c|c|c|c|}
\hline \multicolumn{2}{|c|}{ ASSOCATIVE } & \multicolumn{2}{|c|}{ SCHENA } & \multicolumn{2}{|c|}{ NONERELATED } \\
\hline PFaUE & TARGET & PRME & TARGET & PQME & TARGET \\
\hline BEE & sTiva & STAGES & DEVELOPNENT & FLOCR & SCFEEN \\
\hline ARPLANE & PLLT & SENSORMOTOR & AEFLEX & MOUNTAN & 82000 \\
\hline OEMTIST & TOOTH & PREOPEFATCAY & CHLOFEN & WAR & EEEKTOR \\
\hline$D Q Y$ & NGHT & CONCRET & CONSERMMIICN & SPCON & HOUR \\
\hline GLOEE & HAND & FORMAL & LOGK & LETTER & $500 A$ \\
\hline WWTER & $\cos$ & AOAPTATON & NUOM EDOE & ATTC & BEACH \\
\hline ONON & TENFS & ASIMLATON & OAGดNZNOTON & PEPFER & ENRTH \\
\hline CHEESE & MOUSE & ACCOOMOOATON & REPRESENTATON & WEOONG & CHOCOUT \\
\hline CLOTH & SPDER & EOLUARLM & PERMANENCE & TUQAR & 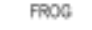 \\
\hline TEMMIS & BNL & SCHEM & CONSTFUCTION & SKRT & Jam \\
\hline BLUE & SKY & EPSTEMOLOGY & PAGEET & PISTOL & TRAL \\
\hline CON & MUK & SYMEa & INTERACTON & METER & COFNER \\
\hline SMOKE & TCEACO & STRUCTUAE & ACTICN & OCEN & OFEFA \\
\hline CACUS & clom & OECENTRALIZE & EPSTEMC & PORT & NOTEBOCK \\
\hline SHEEP & wod & NTEWGENCE & MCFAL & Dou & ONGEN \\
\hline
\end{tabular}

\section{Results method 2}

Left panel from Figure 6 shows the students' performance in the semantic priming study before and after the course. An ANOVA analysis showed a significant main effect for word recognition $\mathrm{F}(1$, $43)=5.5809, \mathrm{p}=0.02275$. Whereas recognition times for associatively related words before and after the course were not significantly different $(\mathrm{F}(1,43)=$ 2.50, $\mathrm{p}=0.1153)$, recognition of schemata related was different at the beginning and at the end of a learning process $(\mathrm{F}(1,43)=15.33, \mathrm{p}=0.00031)$. For space reasons non related words are not shown, but they were recognized differently from both semantically related word sets. The right panel in Figure 6 shows bachelor students' recognition times for schema related words based on conceptual definitions to ten target concepts from a computer usability course. It seems that second semester (no significant performance differences before and after the course) students already were familiar with the course content due to the context they were already submerged. That is even when students successfully passed the course they did not learned anything knew, they previously learned the course content by extra-curricular activities.
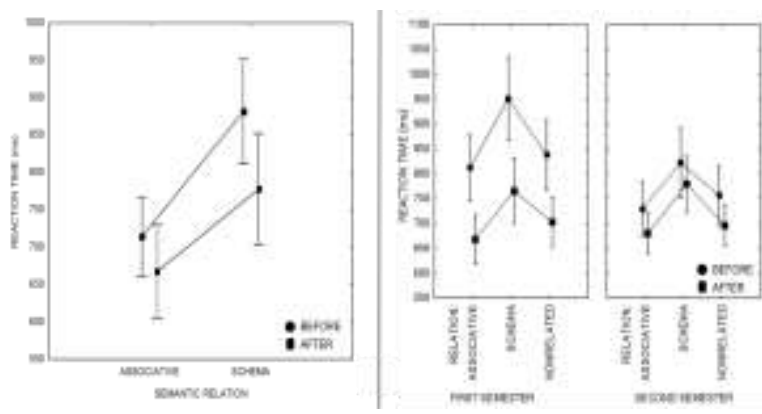

Figure 6. Students have faster recognition of schemata related words only after a course on
Piaget's theory (Left panel). If students possess previous knowledge of a course content (right panel, second semester) then no priming effects are obtained due to course training like in a course of beginners (right panel, first semester)

\section{Discussion}

A cognitive constructive assessment of learning (no matter the used tool) can be considered as a window to observe what actually takes place over the trajectory of a student learning. Then responsive assessment of learning according to the current research, supports or confirms long term consolidation of schemata behavior described by a constructive assessment approach. However, constructive and responsive measurement cannot be understood as separate or orthogonal additive factors to evaluate knowledge acquisition but as dynamic mutually constraining factors. For instance, in the previous examples of mental representations obtained by constructive assessment, these were used to develop responsive assessment of learning. In turn, responsive assessment serves to tune the contents to be evaluated in constructive assessment. For example, selecting a new schema for the second semester of computer usability (right panel in Figure 6).

Because of this schemata concept organization and its underlying net structure leave a footprint over response time patterns in each student, this empowers neural networks with a capacity to distinguish students who have integrated new information in their lexicon from those who did not as it is proposed by the Morales et al computerized system of e-assessment $[12,13]$.

Two main additional aspects can be observed from this alternative method to asses learning: A) It is designed to evaluate what is learned by a student and not to evaluate what is not learned and B) The system evaluates how students signify an event or object due to learning, since natural semantic networks were created to explore how human mental representations underlie human meaning.

More research is on demand and at the current time this evaluation system is being implemented on line in three different main Universities of Mexico for research porpoises. It is intended to be scaled as a nationwide form of alternative assessment of elearning capable to provide simplified reports of cognitive constructive knowledge acquisitions to teachers on several knowledge domains from different geographic regions (cultural differences in terms of meaning are expected). It will also provide a service to evaluate students' long term retention of knowledge acquisition through responsive assessment of e-learning. 


\section{References}

[1] van der Linden W. and C. Glas, Elements of Adaptive Testing, Springer, New York, 2010.

[2] Ifenthaler D., P. Pirnay-Dummer, and N. M. Seel, Computer-based diagnostics and systematic analysis of knowledge, Springer, New York, 2010.

[3] Clariana R.B. (2010a) 'Multi-decision approaches for eliciting knowledge stuctures' in Ifenthaler, P. PirnayDummer, and N. M. Seel (eds.), Computer-based diagnostics and systematic analysis of knowledge, Springer, New York, 2010, Chap. 4, pp. 41-60.

[4] Clariana R.B. (2010b) 'Deriving individual and group knowledge structure from network diagrams and from essays' in Ifenthaler, P. Pirnay-Dummer, and N. M. Seel (eds.), Computer-based diagnostics and systematic analysis of knowledge, Springer, New York, 2010, Chap. 7, pp. 117-131.

[5] C.D. Holley and D.F. Dansereau (1984) 'Networking: The technique and the empirical evidence' in C.D. Holley and D.F. Dansereau (eds.), Spatial learning strategies: Techniques, applications and related issues, Academic Press, Inc., New York, Chap. 4, pp. 81-108.

[6] Hyerle D., Visual Tools for transforming information into knowledge (2nd Edition), Corwing Press, Thousand Oaks, California, 2009.

[7] Rainer Lütticke (2005) 'Using semantic networks for assessment of learners' answers' in Proceedings of the Sixth International Conference on Advanced Learning Technologies (ICALT'06), IEEE Computer Society, Los Alamitos, CA, 1070-1072.

[8] Seel, N. M. (2010) 'Essentials of computer-cased diagnostics of Learning and cognition' in Ifenthaler, P. Pirnay-Dummer, and N. M. Seel (eds.), Computer-based diagnostics and systematic analysis of knowledge, Springer, New York, 2010, Chap. 1, pp. 3-14.

[9] Lachman R., J. Lachman, and E. Butterfield, Cognitive psychology and information processing, Journal, Erlbaum and Associates, Hillsdale New Jersey, 1979.

[10] Harris, D. (2015). Proceedings of 12th international conference, EPCE 2015 held as part of HCI international 2015, Los Angeles, CA, USA: Engineering psychology and cognitive ergonomics, Springer, UK, August 2-7, 2015, LNAI 9174

[11] E.O. Lopez, G.E., Morales, I. Hedlefs and C.J. Gonzalez, 'New empirical directions to evaluate online learning' International Journal of Advances in Psychology, Science and Engineering Publishing Company (SEP), USA, 2014, vol. 3(2), pp. 40-47.

[12] G.E. Morales-Martinez and E.O. Lopez-Ramirez, 'New approaches to e-cognitive assessment of e-learning' International Journal for e-Learning Security (IJeLS), Infonomics Society, UK, 2015, vol.5(2), pp. 449-453.
[13] G.E. Morales-Martinez and M.G. Santos-Alcantara, 'Alternative Empirical Directions to Evaluate Schemata Organization and Meaning' Advances in Social Sciences Research Journal, Society for Science and Education, UK, 2015, vol. 2(9), pp. 51-58.

[14] C.J. Gonzalez, E.O. Lopez and G.E. Morales, 'Evaluating moral schemata learning' International Journal of Advances in Psychology' Advances in Social Sciences Research Journal, Society for Science and Education, UK, 2013, vol. 2(2), pp. 130-136.

[15]Lopez E.O., Schematically related Word Recognition, Doctoral thesis, UMI Publications, University of Wisconsin-Madison, USA, 1996.

[16] Lopez E.O. and J. Theios (1996), 'Single word schemata priming: a connectionist approach' in Proceedings of The 69th Annual Meeting of the Midwestern Psychological Association, Midwestern Psychological Association, Chicago, IL.

[17] J.G. Figueroa, G.E. Gonzales and V.M. Solis, 'An approach to the problem of meaning: Semantic networks' Journal of Psycholinguistic Research, Plenum Publishing Corporation, New York, US., 1975 vol. 5(2), pp. 107115.

[18]A. Nematzadeh, A. Fazly, and S. Stevenson, (2011) 'A computational study of late talking in word meaning acquisition' in Proceedings of the 33rd Annual Meeting of the Cognitive Science Society (CogSci 11), Cognitive Science Society, Austin, TX, 705-710.

[19] A. Nematzadeh, A. Fazly, and S. Stevenson, (2012) 'Interaction of word learning and semantic category formation in late talking' in Proceedings of the 34rd Annual Meeting of the Cognitive Science Society (CogSci 12), Cognitive Science Society, Austin, TX, 2085-2090.

[20] M. Steyvers, and B.J. Tenembaum, 'The large scale structure of semantic netwoks: Statistic analysis and a model of semantic growth' Cognitive Science, Cognitive Science Society, USA., 2005, 29, 41-78.

[21] Bersano-Méndez N.I., S.E. Schaeffer, and J. BustosJiménez (2012) 'Metrics and models for social networks' in A. Ajith and H. Aboul-Ella (eds.), Computational social networks: tools, perspectives and applications, Springer, London, Chap. 5, pp. 115-142.

[22] Rumelhart E., P. Smolensky, J.L. McClelland, and G.E. Hinton (1986) 'Schemata and sequential thought processes' in J.L., McClelland, D. E. Rumelhart, and the PDP research group (eds.), Parallel distributed processing: Explorations in the microstructure of cognition, Academic Press, Inc., New York, vol.2 (Psychological and biological models), MIT Press, Massachusetts, pp. 81-108.

[23] M.A. Conway, G. Cohen, and N. Stanhope, 'On the Very Long-Term Retention of Knowledge Acquired Through Formal Education: Twelve Years of Cognitive Psychology', Journal of Experimental Psychology: General, Psychological Association, USA, 1991, vol. 120, pp. 395-409. 
[24] M.A. Conway, G. Cohen, and N. Stanhope, 'Very long term memory for knowledge acquired at school and university', Applied Cognitive Psychology, Wiley Online library, USA, 1992, vol. 19(6), pp. 467- 482.

[25] Mcnamara T.P., Semantic Priming: Perspectives from Memory and Word Recognition (Essays in Cognitive Psychology), Psychology Press Taylor \& Francis Group, New York, 2005.

[26] S. Becker, M. Moscovitch, M. Behrman, and S. Joordens, 'Long-term semantic priming: A computational account and empirical evidence' Journal of experimental psychology: Learning, Memory and Cognition, 1997, 1059-1082. 